\title{
Optimal ownership in joint ventures with contributions of asymmetric partners
}

M. Marinucci

Discussion Paper 2008-16

\section{Département des Sciences Économiques de l'Université catholique de Louvain}




\title{
CORE DISCUSSION PAPER
}

$2008 / 23$

\section{Optimal ownership in joint ventures with contributions of asymmetric partners}

\author{
Marco MARINUCCI ${ }^{1}$
}

April 2008

\begin{abstract}
This paper faces two questions concerning Joint Ventures (JV) agreements. First, we study how the partners contribution affect the creation and the profit sharing of a JV when partners' effort is not observable. Then, we see whether such agreements are easier to enforce when the decision on JV profit sharing among partners is either delegated to the independent JV management (Management Sharing) or jointly taken by partners (Coordinated Sharing). We find that the firm whose effort has a higher impact on the JV's profits should have a larger profit shares. Moreover, a Management sharing ensures, at least in some cases, a wider range of self-enforceable JV agreements.
\end{abstract}

Keywords: joint ventures, strategic alliances, ownership structure, asymmetries.

JEL Classification: D43, L13, L14, L22

${ }^{1}$ CORE, Université catholique de Louvain, Belgium. E-mail: marco.marinucci@uclouvain.be

I would like to thank Paul Belleflamme, Pierre Picard, Alessandro Sterlacchini, Vincent Vannetelbosch for their useful comments as well as Emanuele Forlani, Carmen Pagliari, Daniela Tellone and Skerdilajda Zanaj for their helpful discussions. Many thanks also to all the participants at the III seminario SIEPI, LUISS, Rome; the Seminario DMQTE, Università degli Studi "G. d'Annunzio", Pescara and the $1^{\text {st }}$ Doctoral Meeting of Montpellier. The support of the FNRS (Fonds National de la Recherche Scientifique) is also gratefully acknowledged. The usual disclaimers hold.

This paper presents research results of the Belgian Program on Interuniversity Poles of Attraction initiated by the Belgian State, Prime Minister's Office, Science Policy Programming. The scientific responsibility is assumed by the author. 



\section{Introduction}

JVs are contracts whereby firms decide to jointly invest in order to improve their individual competitiveness. In the last two decades this kind of cooperation significantly increased, specially for R\&D and International Joint Ventures. ${ }^{1}$ The main motivation of this success is the jointly exploitation of partners' skills. Research Joint ventures (RJV) allow to internalize R\&D spillover effects and also to save on R\&D costs. ${ }^{2}$ International Joint Ventures are used by multinational enterprises (MNE) to enter developing countries markets, whereas local partners can access new technologies and know-how. Also governments and institutions fostered the formation of JVs by creating programmes and subsidies. Think, for example, of the NCRA act and its amendments in U.S. ${ }^{3}$ or the JEV programme in EU. ${ }^{4}$ Unfortunately, JV agreements are not easy to enforce not only because of the moral hazard problems among partners, ${ }^{5}$ but also because of their different capacity to contribute to the creation of the JV. That is why MNEs decide to form a JV only when they find local partners able to positively contribute to the JV profits or why the promotion of JVs through institutional programs can fail. From this point of view, investigating on the asymmetric partners contribution together with moral hazard problems can explain, at least partially, why MNE prefers to create JV in some countries rather than in others or why EU programs like JOP and ECIP failed in their objectives whereas the JEV program is still operating. 6

The study of how partners' asymmetry affects the creation and the profit sharing of JVs has already been covered in the literature. Veugelers and Kesteloot [18] analyze the creation of a Research Joint Venture when partners have a dif-

\footnotetext{
1 "The incidence of joint ventures is increasing especially in sectors where innovation costs and/or competition are increasing" OECD [17].

${ }^{2}$ The most influential paper in the literature concerning the internalization of $R \& D$ spillovers is undoubtedly d'Aspremont-Jacquemin [3]. See also Caloghirou et al. [7] and Hagerdoon et al. [11] for a survey on research partnerships.

${ }^{3}$ The National Cooperative Research Act (NCRA) was approved in 1986 to boost R\&D cooperation among U.S. firms. Basically, it weakened some antitrust rules for all the firms willing to create Research Joint Ventures. During the first half of the '90, it was extended also to other forms of JVs.

${ }^{4}$ The JEV (Joint European Ventures) program offers a financial support (max 100.000 Euros) to all EU firms that want to create a JV with the condition that they should not belong to the same country.

${ }^{5}$ As pointed out by Nakamura and Yeung [16]: "When the supplying of effort is not readily observable, a supplying parent has the incentive and the opportunity to undersupply its effort".

6 "JOP Programme" aimed to promote the creation of JV between EU firms with others from the ex-soviet block. ECIP was built to foster the cooperation among EU firms with Latin-American ones. Both programs have been suppressed in 1999 because of their negligible results.
} 
ferent R\&D efficiency and/ or absorptive capacity. What they find is that RJV are less stable when the absorptive capacity is low and/or the R\&D efficiency of a partner is sufficiently high. On the other hand, Belleflamme and Bloch [5] study the creation of a JV when partners have different production efficiency and operate in complementary/substitute market structures. They show that a more efficient partner should have a larger share of the JV profits. Paying attention to International Joint Ventures, Lin and Saggi [13] try to understand how the ownership structure affects the incentive of a more productive partner (i.e. MNE) to upgrade its input for the JV production. They also see whether upgrading an input could affect the JV ownership structure. Their main finding is that, when the JV profit shares are imposed by local governments, a MNE has lower incentives to upgrade its input. According to this result, they also suggest that JV profits are maximized when the most productive firm has a larger share.

We propose a model where the partners' efforts have a different impact on JV profits. We first study how such asymmetry influences the creation and the ownership structure when partners' investments are not observable. Then, we see whether a JV agreement is easier to enforce when the decision on JV profit sharing is delegated to the independent JV management (Management Sharing) rather than being jointly taken by partners (Coordinated Sharing). To the best of our knowledge, the relevance of this last question is not yet faced in the literature. ${ }^{7}$ Our study suggests three interesting results.

First, similarly to Belleflamme and Bloch [5] and Lin and Saggi [13], we find that the firm whose effort has a highest impact on JV profits should have a larger profit shares. Furthermore, such firm gets a lower share under "Coordinated sharing" than in the case of "Management sharing". This because in the latter sharing rule the management set the shares also taking into account the complementarity degree of the partners' investment. Finally, we show that Management sharing ensures, at least in some cases, a wider range of selfenforceable JV agreements so that it can be an alternative sharing rule to create a JV whenever Coordinated sharing is not enforceable.

It is worth to mention that we also base our model on one of the most important criticisms made by some business scholars to the residual rights approach: ${ }^{8}$

\footnotetext{
${ }^{7}$ In their hidden information problem, Darrough and Stoughton [8] solve their profit sharing scheme using the JV management as ruler. However, they do not consider the case where partners jointly decide the optimal shares.

${ }^{8}$ In particular, according to Grossman and Hart [10] and Hart and Moore [12] seminal papers, JV agreements should be considered as an "incomplete contracts" problem where the optimal ownership share (i.e. the profit share and the control of the JV) should be assesed
} 
the ownership structure may reflect the relevance of partners contribution to the JV. ${ }^{9}$ Furthermore, since this criticism has been validated only with empirical studies,${ }^{10}$ our work can be also seen as a first attempt to give a theoretical background to such point of view.

In the next section we introduce some basic hypotheses of the model whereas in Section 3 we analyze the JV agreement when partners'effort is observable. Then we find the optimal JV profit shares when the decision is either coordinated among partners (Section 4) or delegated to the JV management (Section 5). In section 6 we compare these optimal shares looking at the self-enforceability of the JV agreement. Some concluding remarks are left in the last section.

\section{Model}

In the rest of the paper, the following assumptions hold.

Profitability Assume that two firms $i=1,2$ want to create an independent JV in order to develop a new product. With linear investment costs, the total net benefit from the cooperation is

$$
\pi_{J V}\left(a_{1}, a_{2}, \varepsilon\right)-a_{1}-a_{2} \geq 0
$$

where $\pi_{J V}\left(a_{1}, a_{2}, \varepsilon\right)$ is the Joint Venture profit, $a_{i}>0$ is the amount invested by firm $i$ and $\varepsilon$ is a random shock distributed with zero mean and variance $\sigma^{2}$. Since the performance of the JV is uncertain, the partners decision of creating it, as well as their strategies, will be taken according to the expected JV profits $\Pi_{J V}\left(a_{1}, a_{2}\right)$. Consequently, a JV will be created only when

$$
\Pi_{J V}\left(a_{1}, a_{2}\right)-a_{1}-a_{2} \geq 0
$$

Moreover, the existence of a random shock implies that, whenever the effort is not observable, each parental firm cannot distinguish whether a bad performance of the JV is due either to a defection of the other partner or to the random shock.

\footnotetext{
according to the attribution of the so called "residual rights".

${ }^{9}$ Makino and Beamish [14] summarized such criticisms finding four main limits to the "residual rights" approach: 1) control can be exercised through non-ownership mechanisms; 2) even with a larger ownership, a partner could be not able to control the JV operation; 3) the minority partner could have a dominant control of a specific activity in the JV 4) the ownership position may also represent the relative importance of partner contributions to the $J V$.

${ }^{10}$ For example, using a U.S. database, Blodgett [6] shows that partners with higher contribution in technology and know-how usually gets a higher share than firms who contribute to the JV with commercial or logistic support. See Makino and Beamish [14] for further references.
} 
Strict Complementarity Partners' investments are strong complements, namely, the JV profit function is increasing and strictly concave with respect to the invested assets

$$
\frac{\partial^{2} \Pi_{J V}\left(a_{1}, a_{2}\right)}{\partial a_{1} \partial a_{2}}>0 \quad \frac{\partial^{2} \Pi_{J V}\left(a_{1}, a_{2}\right)}{\partial a_{1}^{2}}<0 \quad \operatorname{det} H_{J V}>0
$$

where $H_{J V}$ is the Hessian matrix of $\Pi_{J V} \cdot{ }^{11}$ Such assumption is quite common in the literature ${ }^{12}$ and reasonable if we think that firms create Joint Ventures in order to benefit from synergies among their skills. A simple way to represent such strict complementarity is to consider the following JV profit structure

$$
\Pi_{J V}\left(a_{1}, a_{2}\right)=\Pi_{J V}\left(a_{1}^{\alpha_{1}} a_{2}^{\alpha_{2}}\right)
$$

with $\alpha_{1}, \alpha_{2} \in(0,1)$. For the sake of simplicity, we will replace $\Pi_{J V}\left(a_{1}^{\alpha_{1}} a_{2}^{\alpha_{2}}\right)$ with $\Pi_{J V}(a)$ whenever the notation becomes too cumbersome.

No side payments Furthermore, side payments are not allowed between partners. We make this assumption because direct transfers are in general more usual when JV's are not new legal entities as supposed in our case. ${ }^{13}$ Moreover, as pointed out by Asiedu and Esfahani [2], in International Joint Ventures side payments could be forbidden by local governments in order to retain more rents in the country. ${ }^{14}$

Sharing schemes and timing In the paper we consider two possible JV profit sharing schemes. In the first one, called Coordinated Sharing, parent firms first jointly decide their JV profit shares $(s, 1-s)$ in order to maximize their cooperative profits. In the second, called Management Sharing, the decision about the JV profit shares is immediately delegated to the independent JV management whose objective is to maximize the JV profits. The timing of the model can be summarized as follows

\footnotetext{
${ }^{11}$ An alternative way to define strong complementarity requires that investments of both firms are necessary to have strictly positive profits. Formally$$
\Pi_{J V}\left(a_{1}, 0\right)=\Pi_{J V}\left(0, a_{2}\right)=0
$$

${ }^{12}$ See for example Anbarci et al. [1] for Research Joint Ventures.

${ }^{13}$ Think for example to the typical Research Joint Venture where a large pharmaceutical firm funds a small biotech one to develop new technologies, products etc. See also Freshfield Bruckhaus Deringer [9] for a legal point of view.

${ }^{14}$ Another reason to reject the direct transfers assumption is suggested by Nakamura [15]: side payments in the context of international Joint Ventures correspond to the contractible aspects of the use of intangible assets (i.e. technology and name brand) which are usually contracted away from the agreement in the form of royalties and/or lump-sum payments.
} 
1. each firm has to decide whether or not to participate to the JV;

2. if both firms want to create the JV, then they have to choose either Coordinated or Management sharing as a JV profit sharing rule;

3. the JV profits shares $(s, 1-s)$ are therefore set according to the sharing rule chosen by the partners;

4. once these shares are defined, each firm invests an amount of assets $a_{i}(s)>$ 0 in order to make the JV operative;

5. the direction of the JV is then delegated to the independent management who maximizes the JV profits.

To avoid useless complications there are no moral hazard problems between partners and management: the effort of the latter is always perfectly observable.

In the next section, we analyze the Coordinated Sharing scheme when the partners' effort is perfectly observable. The Management Sharing will be not considered because, under perfect observability, partners can always define a self-enforceable JV contract without using an alternative sharing decisioner.

\section{Coordinated Sharing with perfect observabil- ity}

In the Coordinated Sharing, parental firms jointly choose the profit shares $(s, 1-s)$ such that, fostering the optimal effort levels, partners maximize their cooperative profits $\Pi_{C}$. Of course, each firm has the incentive to ask for a higher share but reducing too much the share of the other firm would induce a reduction of its effort. Given this trade-off and assuming the perfect observability of partners effort, the problem faced by the parental firms is

$$
\begin{cases}\max _{s} \Pi_{C}=\Pi_{J V}\left(a_{1}^{\alpha_{1}} a_{2}^{\alpha_{2}}\right)-a_{1}-a_{2} & \\ \text { s.t. } & \text { IR } 1 \\ s \Pi_{J V}\left(a_{1}^{\alpha_{1}} a_{2}^{\alpha_{2}}\right)-a_{1} \geq 0 & I R 2 \\ (1-s) \Pi_{J V}\left(a_{1}^{\alpha_{1}} a_{2}^{\alpha_{2}}\right)-a_{2} \geq 0 & I R\end{cases}
$$

where IR1 and IR2 are the individual rationality constraints of firm 1 and 2 respectively. Since the marginal benefits for firm $i$ to invest $a_{i}$ in the JV is

$$
\frac{\partial \Pi_{C}}{\partial a_{i}}=\frac{\alpha_{i} a_{j}^{\alpha_{j}} \Pi_{J V}^{\prime}(a)}{a_{i}^{1-\alpha_{i}}}-1
$$


the solution is interior and unique because the following conditions

$$
\left.\frac{\partial \Pi_{C}}{\partial a_{i}}\right|_{a_{i} \rightarrow 0}>0 \quad ;\left.\quad \frac{\partial \Pi_{C}}{\partial a_{i}}\right|_{a_{i} \rightarrow \infty}<0
$$

are always satisfied for each $a_{i}>0$. On the other side, we can rewrite the two

IR constraints as a function of $s$

$$
\frac{a_{1}}{\Pi_{J V}(a)} \leq s \leq 1-\frac{a_{2}}{\Pi_{J V}(a)}
$$

so that they are satisfied only when $s$ is in the above interval range. Finally, in order to find the optimal investment strategy we can use the following first order conditions of $\Pi_{C}$

$$
\begin{aligned}
\frac{\partial \Pi_{C}}{\partial a_{1}} & =\alpha_{1} \quad a_{1}^{\alpha_{1}-1} a_{2}^{\alpha_{2}} \Pi_{J V}^{\prime}(a)-1=0 \\
\frac{\partial \Pi_{C}}{\partial a_{2}} & =\alpha_{2} \quad a_{1}^{\alpha_{1}} a_{2}^{\alpha_{2}-1} \Pi_{J V}^{\prime}(a)-1=0 \\
\Rightarrow a_{2} & =\frac{\alpha_{2}}{\alpha_{1}} a_{1}
\end{aligned}
$$

which show that there is a non-symmetric equilibrium whenever partners effort has a different impact on JV profits (i.e. $\alpha_{i} \neq \alpha_{j}$ ). For example, for $\alpha_{1}>\alpha_{2}$, firm 1 has a higher "impact" on $\Pi_{J V}$ and it should invest more than firm 2 to maximize $\Pi_{C}$. Moreover, another important feature is that a higher impact of firm 1 effort makes IR1 constraint more difficult to satisfy. In the next two sections we study the Coordinated and Management sharing schemes when the effort of parental firms is not observable.

\section{Coordinated Sharing with non observable ef- forts}

In the case of Coordinated Sharing and non observable efforts, parental firms face a doubled-sided moral hazard problem. As principal, each firm wants to maximize the effort of the other. As agent, each partner has an incentive to free-ride by reducing its own effort because it cannot be punished insofar as the performance of the JV depends also on a random shock. Consequently, the only second-best solution comes out when the cooperative profits are maximized 
according to the incentive constraints of each partner (IC1 and IC2)

$$
\begin{cases}\max _{s} \Pi_{C}=\Pi_{J V}\left(a_{1}^{\alpha_{1}} a_{2}^{\alpha_{2}}\right)-a_{1}-a_{2} & \\ \text { s.t. } & \\ a_{1} \in \operatorname{argmax} \Pi_{J V, 1}=s \Pi_{J V}\left(a_{1}^{\alpha_{1}} a_{2}^{\alpha_{2}}\right)-a_{1} & I C 1 \\ a_{2} \in \operatorname{argmax} \Pi_{J V, 2}=(1-s) \Pi_{J V}\left(a_{1}^{\alpha_{1}} a_{2}^{\alpha_{2}}\right)-a_{2} & I C 2 \\ +I R 1 & \\ +I R 2 & \end{cases}
$$

Where $\Pi_{J V, i}$ is the payoff of firm $i$ when it participates to the JV. As suggested by Belleflamme and Bloch [5], such problem can be solved by totally differentiating $\Pi_{C}$ with respect to $s$

$$
\frac{d \Pi_{C}}{d s}=\frac{\partial \Pi_{C}}{\partial a_{1}} \frac{\partial a_{1}}{\partial s}+\frac{\partial \Pi_{C}}{\partial a_{2}} \frac{\partial a_{2}}{\partial s}
$$

In fact, knowing that firms' investment strategies depend on the JV profit shares, this condition allows us to study when an increase of $s$ has a positive effect on the objective function: whenever $\frac{d \Pi_{C}}{d s}>0$, a further increase of $s$ is more desirable because it ensures higher cooperative profits. The opposite obviously occurs for $\frac{d \Pi_{C}}{d s}<0$.

To define the optimal share, a first step is to use the partners' implicit reaction function (obtained from the incentive constraints)

$$
\begin{aligned}
& \frac{\partial \Pi_{J V, 1}}{\partial a_{1}}=0 \Leftrightarrow s \frac{\partial \Pi_{J V}\left(a_{1}^{\alpha_{1}} a_{2}^{\alpha_{2}}\right)}{\partial a_{1}}-1=0 \\
& \frac{\partial \Pi_{J V, 2}}{\partial a_{2}}=0 \Leftrightarrow(1-s) \frac{\partial \Pi_{J V}\left(a_{1}^{\alpha_{1}} a_{2}^{\alpha_{2}}\right)}{\partial a_{2}}-1=0
\end{aligned}
$$

to rewrite the partial effect of the investments on the cooperative profits as follows

$$
\begin{aligned}
& \frac{\partial \Pi_{C}}{\partial a_{1}}=(1-s) \frac{\Pi_{J V}\left(a_{1}^{\alpha_{1}} a_{2}^{\alpha_{2}}\right)}{\partial a_{1}}+\underbrace{s \frac{\Pi_{J V}\left(a_{1}^{\alpha_{1}} a_{2}^{\alpha_{2}}\right)}{\partial a_{1}}-1}_{0} \Rightarrow \\
& \frac{\partial \Pi_{C}}{\partial a_{1}}=(1-s) \frac{\Pi_{J V}\left(a_{1}^{\alpha_{1}} a_{2}^{\alpha_{2}}\right)}{\partial a_{1}}
\end{aligned}
$$




$$
\begin{aligned}
& \frac{\partial \Pi_{C}}{\partial a_{2}}=s \frac{\Pi_{J V}\left(a_{1}^{\alpha_{1}} a_{2}^{\alpha_{2}}\right)}{\partial a_{2}}+\underbrace{(1-s) \frac{\Pi_{J V}\left(a_{1}^{\alpha_{1}} a_{2}^{\alpha_{2}}\right)}{\partial a_{2}}-1}_{0} \Rightarrow \\
& \frac{\partial \Pi_{C}}{\partial a_{2}}=s \frac{\Pi_{J V}\left(a_{1}^{\alpha_{1}} a_{2}^{\alpha_{2}}\right)}{\partial a_{2}}
\end{aligned}
$$

so that the total differential becomes

$$
\frac{d \Pi_{C}}{d s}=(1-s) \frac{\partial \Pi_{J V}(a)}{\partial a_{1}} \frac{\partial a_{1}}{\partial s}+s \frac{\partial \Pi_{J V}(a)}{\partial a_{2}} \frac{\partial a_{2}}{\partial s}
$$

The second step is to explicit the partial effects of $s$ on $a_{i}$. For this purpose, we totally differentiate the incentive constraints of parental firms with respect to $s$ and get a system of two equations

$$
\left\{\begin{array}{l}
\frac{\partial \Pi_{J V}(a)}{\partial a_{1}}+s\left(\frac{\partial^{2} \Pi_{J V}(a)}{\partial a_{1}^{2}} \frac{\partial a_{1}}{\partial s}+\frac{\partial^{2} \Pi_{J V}(a)}{\partial a_{1} \partial a_{2}} \frac{\partial a_{2}}{\partial s}\right)=0 \\
-\frac{\partial \Pi_{J V}(a)}{\partial a_{2}}+(1-s)\left(\frac{\partial^{2} \Pi_{J V}(a)}{\partial a_{1} \partial a_{2}} \frac{\partial a_{1}}{\partial s}+\frac{\partial^{2} \Pi_{J V}(a)}{\partial a_{2}^{2}} \frac{\partial a_{2}}{\partial s}\right)=0
\end{array}\right.
$$

whose unknowns are the partial effects of $s$ on partners effort $a_{i}$. After some calculations, ${ }^{15}$ the following solutions allow us to see how partners modify their optimal investments as $s$ changes ${ }^{16}$

$$
\begin{aligned}
& \frac{\partial a_{1}}{\partial s}=-\frac{s \frac{\partial^{2} \Pi_{J V}(a)}{\partial a_{1} \partial a_{2}} \frac{\partial \Pi_{J V}(a)}{\partial a_{2}}+(1-s) \frac{\partial^{2} \Pi_{J V}(a)}{\partial a_{2}^{2}} \frac{\partial \Pi_{J V}(a)}{\partial a_{1}}}{s(1-s) \operatorname{det} H_{J V}} \\
& \frac{\partial a_{2}}{\partial s}=\frac{s \frac{\partial^{2} \Pi_{J V}(a)}{\partial a_{1}^{2}} \frac{\partial \Pi_{J V}(a)}{\partial a_{2}}+(1-s) \frac{\partial^{2} \Pi_{J V}(a)}{\partial a_{1} \partial a_{2}} \frac{\partial \Pi_{J V}(a)}{\partial a_{1}}}{s(1-s) \operatorname{det} H_{J V}}
\end{aligned}
$$

Substituting these values into Equation (3) and rearranging some terms it is possible to find the following condition

$$
\begin{aligned}
& \frac{d \Pi_{C}}{d s} \geq 0 \Leftrightarrow s^{2}\left[\frac{\partial^{2} \Pi_{J V}(a)}{\partial a_{1}^{2}}\left(\frac{\partial \Pi_{J V}(a)}{\partial a_{2}}\right)^{2}-\frac{\partial^{2} \Pi_{J V}(a)}{\partial a_{2}^{2}}\left(\frac{\partial \Pi_{J V}(a)}{\partial a_{1}}\right)^{2}\right] \\
& -(1-2 s) \frac{\partial^{2} \Pi_{J V}(a)}{\partial a_{2}^{2}}\left(\frac{\partial \Pi_{J V}(a)}{\partial a_{1}}\right)^{2} \geq 0
\end{aligned}
$$

which can be explicited according to our JV profits function as

$$
\begin{aligned}
& \frac{d \Pi_{C}}{d s} \geq 0 \Leftrightarrow s^{2} \Pi_{J V}^{\prime}(a)\left(\alpha_{1}-\alpha_{2}\right)-(1-2 s) \alpha_{1} \\
& \cdot\left[\left(\alpha_{2}-1\right) \Pi_{J V}^{\prime}(a)+\alpha_{2} a \Pi_{J V}^{\prime \prime}(a)\right] \geq 0
\end{aligned}
$$

\footnotetext{
${ }^{15}$ See Appendix A for further details.

${ }^{16}$ Note that when it is near to zero, an increase of $s$ stimulates firm 1 to increase its effort because she can increase further its payoff. The opposite occurs as $s$ approaches one.
} 
As it can be seen, when the firms' investments have a symmetric impact on JV profits (i.e. $\alpha_{1}=\alpha_{2}$ ) the optimal share is $s_{C}^{*}=1 / 2$. On the other hand, in the asymetric case we cannot calculate $s_{C}^{*}$ without specifying the expected Joint Venture profit function $\Pi_{J V}(a)$. This is of course a drawback of our method. ${ }^{17}$ However, we can see when $s_{C}^{*}$ is larger than $1 / 2$ by simply studying the sign of equation (7) at $s=1 / 2$

$$
\frac{d \Pi_{C}}{d s} \geq\left. 0\right|_{s=1 / 2} \Leftrightarrow \alpha_{1} \geq \alpha_{2}
$$

which allows us to state the following

Proposition 1 In a JV agreement where firms jointly decide their profit shares, the firm whose investments have a larger impact on the JV profits must have a larger share.

\section{Management Sharing}

In the case of Management sharing, parent firms delegate the sharing decision to the independent management. Since it is paid to maximize the JV profit, the management must take into account that its sharing decision influences the partners' effort and, consequently, the expected performance of the JV itself. Thereby, when the partners' effort is not observable, the problem faced by the management is ${ }^{18}$

$$
\left\{\begin{array}{l}
\max _{s} \Pi_{M}=\Pi_{J V}\left(a_{1}^{\alpha_{1}} a_{2}^{\alpha_{2}}\right) \\
\text { s.t. } \\
a_{1} \in \operatorname{argmax} \Pi_{J V, 1}=s \Pi_{J V}\left(a_{1}^{\alpha_{1}} a_{2}^{\alpha_{2}}\right)-a_{1} \\
a_{2} \in \operatorname{argmax} \Pi_{J V, 2}=(1-s) \Pi_{J V}\left(a_{1}^{\alpha_{1}} a_{2}^{\alpha_{2}}\right)-a_{2} \\
+I R 1 \\
+I R 2
\end{array}\right.
$$

\footnotetext{
${ }^{17}$ Later on, we propose an example where we specify a JV profit function in order to understand how it is possible to find an optimal ownership share $s_{C}^{*}$.

${ }^{18}$ The problem actually reflects a principal multi-agent problem. However, since the objective function is also included in the incentive constraints, we will adopt the same approach as in the previous case.
} 
Firstly, since the objective function corresponds to the JV profit function, it is increasing and strict concave so that the following conditions for a unique non-trivial solution

$$
\left.\frac{\partial \Pi_{M}}{\partial a_{i}}\right|_{a_{i} \rightarrow 0}>0 \quad ;\left.\quad \frac{\partial \Pi_{M}}{\partial a_{i}}\right|_{a_{i} \rightarrow \infty}<0
$$

are always satisfied.

Secondly, as in the previous section, the optimal ownership scheme comes out by totally differentiating the objective function

$$
\frac{d \Pi_{M}}{d s}=\frac{\partial \Pi_{M}}{\partial a_{1}} \frac{\partial a_{1}}{\partial s}+\frac{\partial \Pi_{M}}{\partial a_{2}} \frac{\partial a_{2}}{\partial s}
$$

In this case, the partial effect of partners' efforts on the JV profit are

$$
\frac{\partial \Pi_{M}}{\partial a_{1}}=\frac{\partial \Pi_{J V}\left(a_{1}^{\alpha_{1}} a_{2}^{\alpha_{2}}\right)}{\partial a_{1}} \quad ; \quad \frac{\partial \Pi_{M}}{\partial a_{2}}=\frac{\partial \Pi_{J V}\left(a_{1}^{\alpha_{1}} a_{2}^{\alpha_{2}}\right)}{\partial a_{2}}
$$

whereas the partial effects of $s$ over partners' effort are the same as in Coordinated sharing because the incentive constraints do not change

$$
\begin{aligned}
\frac{\partial a_{1}}{\partial s} & =-\frac{s \frac{\partial^{2} \Pi_{J V}(a)}{\partial a_{1} \partial a_{2}} \frac{\partial \Pi_{J V}(a)}{\partial a_{2}}+(1-s) \frac{\partial^{2} \Pi_{J V}(a)}{\partial a_{2}^{2}} \frac{\partial \Pi_{J V}(a)}{\partial a_{1}}}{s(1-s) \operatorname{det} H_{J V}} \\
\frac{\partial a_{2}}{\partial s} & =\frac{s \frac{\partial^{2} \Pi_{J V}(a)}{\partial a_{1}^{2}} \frac{\partial \Pi_{J V}(a)}{\partial a_{2}}+(1-s) \frac{\partial^{2} \Pi_{J V}(a)}{\partial a_{1} \partial a_{2}} \frac{\partial \Pi_{J V}(a)}{\partial a_{1}}}{s(1-s) \operatorname{det} H_{J V}}
\end{aligned}
$$

Using these partial derivatives we can define the total effect of $s$ on $\Pi_{M}$ as ${ }^{19}$

$$
\begin{aligned}
& \frac{d \Pi_{M}}{d s} \geq 0 \Leftrightarrow s \frac{\partial^{2} \Pi_{J V}(a)}{\partial a_{1}^{2}}\left(\frac{\partial \Pi_{J V}(a)}{\partial a_{2}}\right)^{2}-(1-s) \frac{\partial^{2} \Pi_{J V}(a)}{\partial a_{2}^{2}}\left(\frac{\partial \Pi_{J V}(a)}{\partial a_{1}}\right)^{2} \\
& +(1-2 s) \frac{\partial^{2} \Pi_{J V}(a)}{\partial a_{1} a_{2}} \frac{\partial \Pi_{J V}(a)}{\partial a_{1}} \frac{\partial \Pi_{J V}(a)}{\partial a_{2}} \geq 0
\end{aligned}
$$

Substituting our JV profit function, we find after some calculations (see Appendix B) the following optimal sharing scheme

$$
\frac{d \Pi_{M}}{d s}=0 \Leftrightarrow s_{M}^{*}=\frac{\alpha_{1}}{\alpha_{1}+\alpha_{2}}
$$

which allows us to state the following

Proposition 2 In a JV agreement where $J V$ management decides on the $J V$ profit shares, the firm whose investments have a larger impact on the JV profits must have a larger share.

Note first that, like in Coordinated sharing, partners get the same share if their efforts have a symmetric effect on JV profit. However, the optimal share $s_{M}^{*}$ does not depend on the JV profit structure. Moreover, the last term in the equation (10) shows that the Management sharing decision is based also on the partners' effort complementarity.

\footnotetext{
${ }^{19}$ See Appendix B for a formal proof.
} 


\section{Coordinated vs. Management sharing}

Making a comparison between Coordinated and Management sharing, both schemes suggest that the firm with a larger contribution capacity should have a higher JV profit share. Yet, we are unable to assess either which of them gives a higher share to the firm with the highest impact or which is the most enforceable sharing rule.

Optimal shares Concerning the first issue, suppose that firm 1 has larger impact on JV profits without loss of generality (i.e. $\alpha_{1}>\alpha_{2}$ ). Given that the JV profit function is increasing and strictly concave, a simple way to check which sharing scheme ensures a higher share is to see the sign of equation (7) at $s=s_{M}^{*}$. A positive value would mean that $s_{M}^{*}$ is suboptimal to maximize joint profits (i.e. $s_{C}^{*}>s_{M}^{*}$ ) whereas, a negative one, would imply that firm 1's share is too high (i.e. $s_{C}^{*}<s_{M}^{*}$ ). Substituting $s_{M}^{*}=\frac{\alpha_{1}}{\alpha_{1}+\alpha_{2}}$ in equation (7) we get the following condition

$$
\frac{d \Pi_{C}}{d s} \geq\left. 0\right|_{s=s_{M}^{*}} \Leftrightarrow \Pi_{J V}^{\prime}(a)\left(1-\alpha_{1}-\alpha_{2}\right)-\left(\alpha_{1}+\alpha_{2}\right) a \Pi_{J V}^{\prime \prime}(a) \leq 0
$$

which is incompatible with a concavity condition of the JV profit function

Proposition 3 In a JV where firm $i$ 's effort has a larger impact on JV profits, firm i gets a higher share in the "Management sharing" than in the "Coordinated sharing".

Proof: Comparing the equation (12) with a concavity condition of the JV profit function

$$
\operatorname{det} H_{J V}>0 \Leftrightarrow \Pi_{J V}^{\prime}(a)\left(1-\alpha_{1}-\alpha_{2}\right)-\left(\alpha_{1}+\alpha_{2}\right) a \Pi_{J V}^{\prime \prime}(a)>0
$$

we can see they are incompatible. Q.E.D.

Enforceability Looking at the enforceability of the JV contract, namely the satisfaction of IR constraints,

$$
\frac{a_{1}}{\Pi_{J V}\left(a_{1}^{\alpha_{1}} a_{2}^{\alpha_{2}}\right)} \leq s \leq 1-\frac{a_{2}}{\Pi_{J V}\left(a_{1}^{\alpha_{1}} a_{2}^{\alpha_{2}}\right)}
$$

Management sharing should lead to a wider range of self enforceable contracts because it maximizes JV profits. On the other hand, since Management sharing also leads to different JV profit shares, partners' efforts $a_{1}$ and $a_{2}$ will be different too. The analysis on the enforceability of the JV agreement should 
be consequently done on a case-by-case basis. Nevertheless, whenever Management sharing allows an easier enforceability, the JV agreement can be enforced only through this sharing scheme. In the following example we show that such situation is not so uncommon as it seems at first sight.

\subsection{An Example}

Let the JV be a monopolist in a market with a linear demand $p\left(q_{J V}\right)=A-q_{J V}$ and a linear cost function which is increasing with respect to $c>0$, decreasing with respect to $a=a_{1}^{\alpha_{1}} a_{2}^{\alpha_{2}}$, and affected by a random shock $\varepsilon$ with zero mean and finite variance $\sigma^{2}$. For example

$$
\pi_{J V}=\left(A-q_{J V}\right) q_{J V}-[A-2 \sqrt{a+\varepsilon-c}] q_{J V}
$$

Note that the square root has a positive argument only when $a+\varepsilon \geq c$. Moreover, the marginal cost is positive if and only if $a+\varepsilon \leq c+A^{2} / 4$. Consequently, in order to have a non-trivial solution we must require that

$$
c \leq a+\varepsilon \leq c+\frac{A^{2}}{4}
$$

Using the FOC we can find the following optimal quantity and the related JV profits

$$
q_{J V}^{*}=(a+\varepsilon-c)^{1 / 2} ; \pi_{J V}^{*}=a+\varepsilon-c
$$

Given that partners must assess their decision according to the expected JV profits then

$$
\Pi_{J V}(a)=E\left(\pi_{J V}^{*}\right)=a-c
$$

so that $\Pi_{J V}^{\prime}(a)=1$ and $\Pi_{J V}^{\prime \prime}(a)=0$. Moreover, in order to have $\Pi_{J V}(a)$ strictly concave we must assume that $\alpha_{1}+\alpha_{2}<1$.

Optimal Shares According to these values, we can use equation (7) to find the optimal Coordinated share

$$
s_{C}^{*}=\frac{\alpha_{1}\left(1-\alpha_{2}\right)-\sqrt{\alpha_{1} \alpha_{2}\left(\alpha_{1}-1\right)\left(\alpha_{2}-1\right)}}{\alpha_{1}-\alpha_{2}} ; \alpha_{1}, \alpha_{2} \in(0,1)
$$

which will be higher (lower) than one half when $\alpha_{1}$ is bigger (smaller) than $\alpha_{2} \cdot{ }^{20}$ As shown in figures 1 and 2 , an increase of $\alpha_{1}$ corresponds to an increase of the share given to firm 1 while the opposite occurs for $\alpha_{2}$ increasing. On

\footnotetext{
${ }^{20}$ Note that $s^{*}$ is always positive because both numerator and denominator are positive whenever $\alpha_{1}>\alpha_{2}$ and negative otherwise. However, the $s_{C}^{*}$ expressed here is valid for $\alpha_{1} \neq \alpha_{2}$. For $\alpha_{1}=\alpha_{2}$, we must use equation (7) to find that the optimal ownership is always equal to one half.
} 


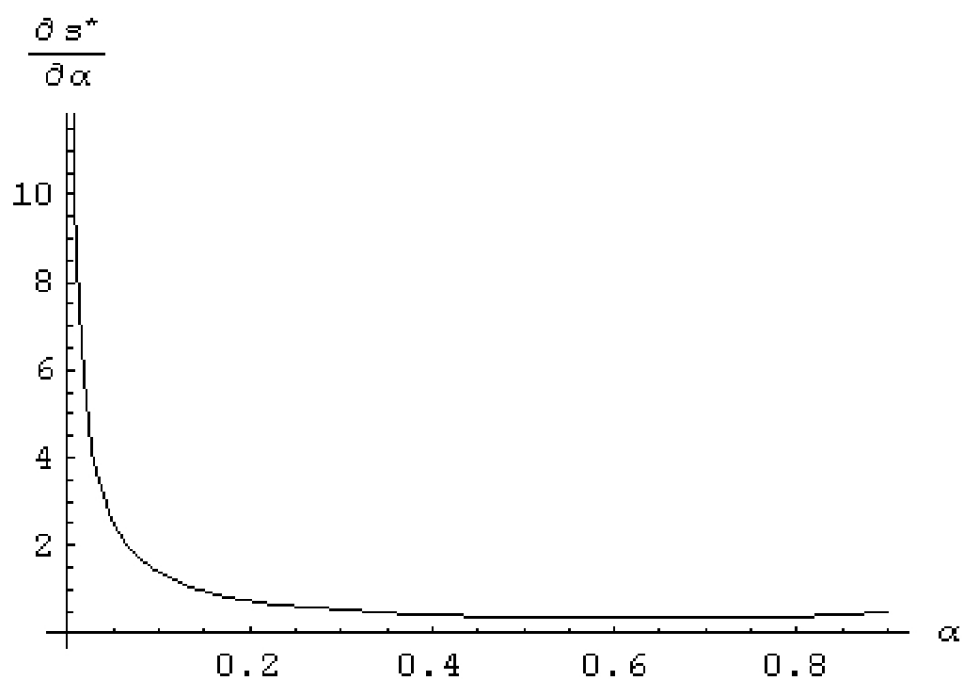

Figure 1: Partial effect of $\alpha_{1}$ on $s_{C}^{*}$ with $\alpha_{2}=0.1$

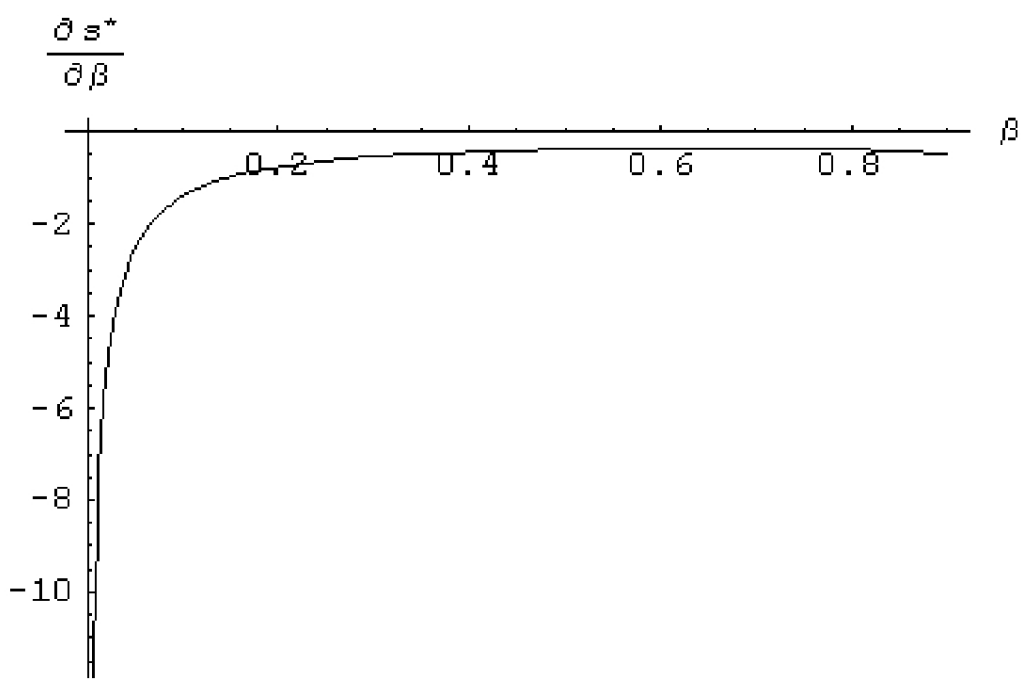

Figure 2: Partial effect of $\alpha_{2}$ on $s_{C}^{*}$ with $\alpha_{1}=0.1$ 
the opposite, the optimal Management share is

$$
s_{M}^{*}=\frac{\alpha_{1}}{\alpha_{1}+\alpha_{2}}
$$

Before discussing the enforceability of the JV, some remarks are needed. First, since the notation is no more cumbersome, in the following we point out that $a_{1}, a_{2}$ and $a=a_{1}^{\alpha_{1}} a_{2}^{\alpha_{2}}$ depend on $s$. Second, recall that Management sharing a) gives higher shares to the firm with the highest impact on JV profits (i.e. $s_{M}^{*}>$ $s_{C}^{*}$ ) and b) produce higher (expected) JV profits than Coordinated sharing, namely $\Pi_{J V}\left(a\left(s_{M}^{*}\right)\right)>\Pi_{J V}\left(a\left(s_{C}^{*}\right)\right)$. Finally, in our case, we can rewrite the partners implicit reaction functions (see equation (4)) as

$$
a_{1}\left(s^{*}\right)=s^{*} \quad \alpha_{1} a\left(s^{*}\right) \quad ; \quad a_{2}\left(s^{*}\right)=\left(1-s^{*}\right) \alpha_{2} a\left(s^{*}\right)
$$

where $s^{*}$ can be either $s_{M}^{*}$ or $s_{C}^{*}$.

Enforceability Let start from the IR constraints

$$
\frac{a_{1}(s)}{a(s)-c} \leq s \leq 1-\frac{a_{2}(s)}{a(s)-c}
$$

we can rewrite IR1 as

$$
\frac{a_{1}(s)}{a(s)-c} \leq s \Rightarrow c s \leq a(s) s-a_{1}(s)
$$

As previouly remarked, in equilibrium $a_{1}\left(s^{*}\right)=s^{*} \alpha_{1} a\left(s^{*}\right)$ so that IR1 becomes

$$
c \leq\left(1-\alpha_{1}\right) a\left(s^{*}\right)
$$

In the same way we can rewrite IR2 $\mathrm{as}^{21}$

$$
c \leq\left(1-\alpha_{2}\right) a\left(s^{*}\right)
$$

Consequently, both IR constraints will be satisfied whenever

$$
c \leq \min \left[\left(1-\alpha_{1}\right) a\left(s^{*}\right) ;\left(1-\alpha_{2}\right) a\left(s^{*}\right)\right]
$$

that is when the JV is not too much costly with respect to the expected benefits (recall that $\left.\Pi_{J V}(a)=a\left(s^{*}\right)\right) \cdot{ }^{22}$ Furthermore, since $\alpha_{1}>\alpha_{2}$, the IR constraints

$$
\begin{aligned}
& { }^{21} \text { In particular } \\
& \quad s \leq 1-\frac{a_{2}(s)}{a(s)-c} \Rightarrow c \leq a(s)-\frac{a_{2}(s)}{(1-s)}
\end{aligned}
$$

Since according to firm 2 best response function $a_{s^{*}}\left(s^{*}\right)=\left(1-s^{*}\right) \alpha_{2} a^{*}$, we get our result. ${ }^{22}$ Note also that, like in the case of perfect effort observability, as firm $i$ has a higher impact on JV profits by a higher $\alpha_{i}$, its IR constraint is more difficult to satisfy. 
in the Coordinated and Management sharing schemes are respectively fullfilled when

$$
c \leq\left(1-\alpha_{1}\right) a\left(s_{C}^{*}\right) ; c \leq\left(1-\alpha_{1}\right) a\left(s_{M}^{*}\right)
$$

which show that the latter scheme ensures a wider range of self enforceable contracts than the former. In particular, whenever

$$
\left(1-\alpha_{1}\right) a\left(s_{C}^{*}\right) \leq c \leq\left(1-\alpha_{1}\right) a\left(s_{M}^{*}\right)
$$

Management sharing makes the JV agreement self enforceable while Coordinated sharing not. Thereby, even though partners will prefer Coordinated sharing because it lead to higher expected profits, there are some cases where they can enforce the JV agreement by only using a Management sharing rule.

Proposition 4 In some cases a JV agreement is self-enforceable only by adopting a Management sharing scheme.

A note about the sharing rule decision Before the concluding remarks, it is worth to mention the existence of a possible disagreement in the choice of the sharing rule. ${ }^{23}$ Since Proposition 3 states that $s_{M}^{*}>s_{C}^{*}$, then firm 1 can get higher individual profits from Management sharing even though this leads to lower joint cooperative profits. This implies that, whenever the two rules are enforceable, firm 1 can desire Management sharing whereas firm 2 prefers Coordinated sharing. Such disagreement cannot be explained by using our model. ${ }^{24}$ However, since we assume that firms want to define at least a cooperative objective function, such problem is left for further research.

\section{Concluding Remarks}

Our paper faces two questions on the enforceability of the JV agreements when partners' effort is not observable. First, we study how a different impact of partners' efforts influence the JV profits sharing among the two firms. Afterwards, we see whether a JV agreement can be easier to enforce when the decision on JV profit sharing is delegated to the independent JV management rather than being jointly taken by partners.

\footnotetext{
${ }^{23}$ Many thanks to Gilles Grandjean to point out this drawback of the model.

${ }^{24}$ We can imagine that such disagreement lead to a) the failure of the JV creation b) a bargaining procedure which lead to one of the two sharing rules c) the default choice for Coordinated sharing insofar as it is the most common way to define a cooperative agreement (think for example to Cartels or Research Joint Ventures where participants maximize their joint profits).
} 
First of all, we find both Coordinated and Management sharing suggesting that the firm whose effort has the highest impact on JV profits should have a larger share. This result is in line with the ones by Belleflamme and Bloch [5] and Lin and Saggi [13] and, since it is based on the different impact of partners effort on JV profit, it gives also a theoretical background to one the most important criticism to the "residual rights" literature.

Our second result is that in some cases a Management sharing can make the JV agreement easier to enforce. Hence, it can be considered a valid alternative rule whenever the JV is not enforceable under a more usual Coordinated sharing. In this way a firm, who can weakly contributes to a $\mathrm{JV}$, is more able to attract a "stronger" partner. On the other hand, governments and institutions can use Management sharing to improve their programs in favor of the cooperation among firms. Even more interestingly, government of developing countries can promote Management sharing rather than imposing suboptimal profit shares which deter multinational enterprises to invest in their nations.

Limits and Extensions Even though interesting, the model has still some limits to take into account. The first one is rather a suggestion for a possible extension. Our results are in fact proved for Joint Ventures with only two partners; however, it would be more interesting if they also hold for JVs with more than two partners. Another drawback of the model is that the optimal Coordinated share cannot be defined unless the JV profit function is specified. Moreover, as already said in the last section, further investigation should be made when partners disagree on the sharing rule to adopt when more than one rule can be enforced. Finally, we assume that the JV management is perfectly observable and independent at the same time. However, a strict control on the management activity can sometimes imply that it is not fully independent to operate as it will.

\section{A Coordinated Sharing}

Let start from equation (5)

$$
\frac{d \Pi_{C}}{d s}=(1-s) \frac{\partial \Pi_{J V}(a)}{\partial a_{1}} \frac{\partial a_{1}}{\text { partials }}+s \frac{\partial \Pi_{J V}(a)}{\partial a_{2}} \frac{\partial a_{2}}{\partial s}
$$

In order to find the optimal share we explicit the partial effects of $s$ on $a_{i}$ by totally differentiating the incentive constraints of parental firms with respect to 
$s$. In this way we can see how these firms modify their investments as $s$ changes

$$
\left\{\begin{array}{l}
\frac{\partial \Pi_{J V}(a)}{\partial a_{1}}+s\left(\frac{\partial^{2} \Pi_{J V}(a)}{\partial a_{1}^{2}} \frac{\partial a_{1}}{\partial s}+\frac{\partial^{2} \Pi_{J V}(a)}{\partial a_{1} \partial a_{2}} \frac{\partial a_{2}}{\partial s}\right)=0 \\
-\frac{\partial \Pi_{J V}(a)}{\partial a_{2}}+(1-s)\left(\frac{\partial^{2} \Pi_{J V}(a)}{\partial a_{1} \partial a_{2}} \frac{\partial a_{1}}{\partial s}+\frac{\partial^{2} \Pi_{J V}(a)}{\partial a_{2}^{2}} \frac{\partial a_{2}}{\partial s}\right)=0
\end{array}\right.
$$

Rearranging some terms we get a system of two equations and two unkowns

$$
\left\{\begin{array}{l}
\underbrace{s \frac{\partial^{2} \Pi_{J V}(a)}{\partial a_{1}^{2}}}_{A} \frac{\partial a_{1}}{\partial s}+\underbrace{s \frac{\partial^{2} \Pi_{J V}(a)}{\partial a_{1} \partial a_{2}}}_{B} \frac{\partial a_{2}}{\partial s}+\underbrace{\frac{\partial \Pi_{J V}(a)}{\partial a_{1}}}_{E}=0 \\
\underbrace{(1-s) \frac{\partial^{2} \Pi_{J V}(a)}{\partial a_{1} \partial a_{2}}}_{C} \frac{\partial a_{1}}{\partial s}+\underbrace{(1-s) \frac{\partial^{2} \Pi_{J V}(a)}{\partial a_{2}^{2}}}_{D} \frac{\partial a_{2}}{\partial s}-\underbrace{\frac{\partial \Pi_{J V}(a)}{\partial a_{2}}}_{F}=0
\end{array}\right.
$$

whose solutions are ${ }^{25}$

$$
\begin{aligned}
& \frac{\partial a_{1}}{\partial s}=-\frac{B F+D E}{A D-B C}= \\
& =-\frac{s \frac{\partial^{2} \Pi_{J V}(a)}{\partial a_{1} \partial a_{2}} \frac{\partial \Pi_{J V}(a)}{\partial a_{2}}+(1-s) \frac{\partial^{2} \Pi_{J V}(a)}{\partial a_{2}^{2}} \frac{\partial \Pi_{J V}(a)}{\partial a_{1}}}{s(1-s) \operatorname{det} H_{J V}} \\
& \frac{\partial a_{2}}{\partial s}=\frac{A F+C E}{A D-B C}= \\
& =\frac{s \frac{\partial^{2} \Pi_{J V}(a)}{\partial a_{1}^{2}} \frac{\partial \Pi_{J V}(a)}{\partial a_{2}}+(1-s) \frac{\partial^{2} \Pi_{J V}(a)}{\partial a_{1} \partial a_{2}} \frac{\partial \Pi_{J V}(a)}{\partial a_{1}}}{s(1-s) \operatorname{det} H_{J V}}
\end{aligned}
$$

Now, using the capital letter notation we can rewrite the total differential as

$$
\frac{d \Pi_{C}}{d s}=(1-s) E\left(-\frac{B F+D E}{A D-B C}\right)+s F \frac{A F+C E}{A D-B C}
$$

Observing that $(1-s) B E F=s C E F$, the total differential becomes

$$
\begin{aligned}
& \frac{d \Pi_{C}}{d s}=\frac{s A F^{2}-(1-s) D E^{2}}{A D-B C}= \\
& =\frac{s^{2} \frac{\partial^{2} \Pi_{J V}(a)}{\partial a_{1}^{2}}\left(\frac{\partial \Pi_{J V}(a)}{\partial a_{2}}\right)^{2}-(1-s)^{2} \frac{\partial^{2} \Pi_{J V}(a)}{\partial a_{2}^{2}}\left(\frac{\partial \Pi_{J V}(a)}{\partial a_{1}}\right)^{2}}{s(1-s) \operatorname{det}\left(H_{J V}\right)}
\end{aligned}
$$

We can ignore the denominator because it is always positive. Rearranging some terms of the numerator we find the following condition

$$
\begin{aligned}
& \frac{d \Pi_{C}}{d s} \geq 0 \Leftrightarrow s^{2}\left[\frac{\partial^{2} \Pi_{J V}(a)}{\partial a_{1}^{2}}\left(\frac{\partial \Pi_{J V}(a)}{\partial a_{2}}\right)^{2}-\frac{\partial^{2} \Pi_{J V}(a)}{\partial a_{2}^{2}}\left(\frac{\partial \Pi_{J V}(a)}{\partial a_{1}}\right)^{2}\right] \\
& -(1-2 s) \frac{\partial^{2} \Pi_{J V}(a)}{\partial a_{2}^{2}}\left(\frac{\partial \Pi_{J V}(a)}{\partial a_{1}}\right)^{2} \geq 0
\end{aligned}
$$

${ }^{25}$ Recall that $\operatorname{det} H_{J V}$ is the determinant of the Hessian matrix of the JV profits. 
which corresponds to our equation (6). Simple calculations show that

$$
\begin{aligned}
& \frac{\partial^{2} \Pi_{J V}(a)}{\partial a_{i}^{2}}\left(\frac{\partial \Pi_{J V}(a)}{\partial a_{j}}\right)^{2}=\alpha_{i} \alpha_{j}^{2} a_{i}^{3 \alpha_{i}-2} a_{j}^{3 \alpha_{j}-2}\left(\Pi_{J V}^{\prime}(a)\right)^{2} . \\
& \cdot\left[\left(\alpha_{i}-1\right) \Pi_{J V}^{\prime}(a)+\alpha_{i} a \Pi_{J V}^{\prime \prime}(a)\right]
\end{aligned}
$$

Hence equation (6) can be rewritten as

$$
\begin{aligned}
& \frac{d \Pi_{C}}{d s} \geq 0 \Leftrightarrow \\
& \alpha_{1} \alpha_{2} a_{1}^{3 \alpha_{1}-2} a_{2}^{3 \alpha_{2}-2}\left(\Pi_{J V}^{\prime}(a)\right)^{2}\left\{s^{2} \Pi_{J V}^{\prime}(a)\left(\alpha_{1}-\alpha_{2}\right)\right. \\
& \left.-(1-2 s) \alpha_{1}\left[\left(\alpha_{2}-1\right) \Pi_{J V}^{\prime}(a)+\alpha_{2} a \Pi_{J V}^{\prime \prime}(a)\right]\right\} \geq 0
\end{aligned}
$$

Since all the terms outside the brackets are strictly positive the condition reduces to

$$
\begin{aligned}
& \frac{d \Pi_{C}}{d s} \geq 0 \Leftrightarrow s^{2} \Pi_{J V}^{\prime}(a)\left(\alpha_{1}-\alpha_{2}\right)-(1-2 s) \alpha_{1} . \\
& \cdot\left[\left(\alpha_{2}-1\right) \Pi_{J V}^{\prime}(a)+\alpha_{2} a \Pi_{J V}^{\prime \prime}(a)\right] \geq 0
\end{aligned}
$$

Which corresponds to our equation (7). Q.E.D

\section{B Management Sharing}

In this section we want to explicit the following total differential

$$
\frac{d \Pi_{M}}{d s}=\frac{\partial \Pi_{M}}{\partial a_{1}} \frac{\partial a_{1}}{\partial s}+\frac{\partial \Pi_{M}}{\partial a_{2}} \frac{\partial a_{2}}{\partial s}
$$

As already pointed out, $\frac{\partial \Pi_{M}}{\partial a_{i}}=\frac{\partial \Pi_{J V}}{\partial a_{i}}$ whereas $\frac{\partial a_{i}}{\partial s}$ is the same as in Coordinated sharing because the incentive constraints do not change. Consequently, we can rewrite coeteris paribus these partial effects using the same notation of the previous section with the only difference that now

$$
\frac{\partial \Pi_{M}}{\partial a_{1}}=\frac{\partial \Pi_{J V}(a)}{\partial a_{1}}=E \quad ; \quad \frac{\partial \Pi_{M}}{\partial a_{2}}=\frac{\partial \Pi_{J V}(a)}{\partial a_{2}}=F
$$

In this way the total differential becomes

$$
\begin{aligned}
& \frac{d \Pi_{M}}{d s}=E\left(-\frac{B F+D E}{A D-B C}\right)+F\left(\frac{A F+C E}{A D-B C}\right)= \\
& =\frac{A F^{2}-D E^{2}+C E F-B E F}{A D-B C}
\end{aligned}
$$


Substituting the related partial derivatives we get

$$
\begin{aligned}
& \frac{d \Pi_{M}}{d s}=\frac{s \frac{\partial^{2} \Pi_{J V}(a)}{\partial a_{1}^{2}}\left(\frac{\partial \Pi_{J V}(a)}{\partial a_{2}}\right)^{2}-(1-s) \frac{\partial^{2} \Pi_{J V}(a)}{\partial a_{2}^{2}}\left(\frac{\partial \Pi_{J V}(a)}{\partial a_{1}}\right)^{2}+}{s(1-s) \operatorname{det}\left(H_{J V}\right)} \\
& \frac{+(1-2 s) \frac{\partial^{2} \Pi_{J V}(a)}{\partial a_{1} \partial a_{2}} \frac{\partial \Pi_{J V}(a)}{\partial a_{1}} \frac{\partial \Pi_{J V}(a)}{\partial a_{2}}}{s(1-s) \operatorname{det}\left(H_{J V}\right)}
\end{aligned}
$$

Since the denominator is always positive, the total effect of $s$ on $\Pi_{M}$ is

$$
\begin{aligned}
& \frac{d \Pi_{M}}{d s} \geq 0 \Leftrightarrow s \frac{\partial^{2} \Pi_{J V}(a)}{\partial a_{1}^{2}}\left(\frac{\partial \Pi_{J V}(a)}{\partial a_{2}}\right)^{2}-(1-s) \frac{\partial^{2} \Pi_{J V}(a)}{\partial a_{2}^{2}}\left(\frac{\partial \Pi_{J V}(a)}{\partial a_{1}}\right)^{2} \\
& +(1-2 s) \frac{\partial^{2} \Pi_{J V}(a)}{\partial a_{1} a_{2}} \frac{\partial \Pi_{J V}(a)}{\partial a_{1}} \frac{\partial \Pi_{J V}(a)}{\partial a_{2}}
\end{aligned}
$$

which corresponds to equation (10). Given that

$$
\begin{aligned}
& \frac{\partial^{2} \Pi_{J V}(a)}{\partial a_{i}^{2}}\left(\frac{\partial \Pi_{J V}(a)}{\partial a_{j}}\right)^{2}= \\
& =\alpha_{i} \alpha_{j}^{2} a_{i}^{3 \alpha_{i}-2} a_{j}^{3 \alpha_{j}-2}\left(\Pi_{J V}^{\prime}(a)\right)^{2}\left[\left(\alpha_{i}-1\right) \Pi_{J V}^{\prime}(a)+\alpha_{i} a \Pi_{J V}^{\prime \prime}(a)\right]
\end{aligned}
$$

whereas

$$
\begin{aligned}
& \frac{\partial^{2} \Pi_{J V}(a)}{\partial a_{1} a_{2}} \frac{\partial \Pi_{J V}(a)}{\partial a_{i}} \frac{\partial \Pi_{J V}(a)}{\partial a_{j}}= \\
& =\left(\alpha_{1} \alpha_{2}\right)^{2} a_{1}^{3 \alpha_{1}-2} a_{2}^{3 \alpha_{2}-2}\left(\Pi_{J V}^{\prime}(a)\right)^{2}\left[\Pi_{J V}^{\prime}(a)+a \Pi_{J V}^{\prime \prime}(a)\right]
\end{aligned}
$$

We can simplify the equation (10) as

$$
\begin{aligned}
& \frac{d \Pi_{M}}{d s} \geq 0 \Leftrightarrow \alpha_{1} \alpha_{2} a_{1}^{3 \alpha_{1}-2} a_{j}^{3 \alpha_{2}-2}\left(\Pi_{J V}^{\prime}(a)\right)^{2} . \\
& \cdot\left\{s \alpha_{2}\left[\left(\alpha_{1}-1\right) \Pi_{J V}^{\prime}(a)+\alpha_{1} a \Pi_{J V}^{\prime \prime}(a)\right]+\right. \\
& -(1-s) \alpha_{1}\left[\left(\alpha_{2}-1\right) \Pi_{J V}^{\prime}(a)+\alpha_{2} a \Pi_{J V}^{\prime \prime}(a)\right] \\
& \left.+(1-2 s) \alpha_{1} \alpha_{2}\left[\Pi_{J V}^{\prime}(a)+a \Pi_{J V}^{\prime \prime}(a)\right]\right\} \geq 0
\end{aligned}
$$

All the terms outside the brackets are always positive, so they can be ignored.

Expliciting all the terms inside brackets we get

$$
\begin{aligned}
& \frac{d \Pi_{M}}{d s} \geq 0 \Leftrightarrow\left[s \alpha_{2}\left(\alpha_{1}-1\right) \Pi_{J V}^{\prime}(a)+s \alpha_{1} \alpha_{2} a \Pi_{J V}^{\prime \prime}(a)\right. \\
& -(1-s) \alpha_{1}\left(\alpha_{2}-1\right) \Pi_{J V}^{\prime}(a)-(1-s) \alpha_{1} \alpha_{2} a \Pi_{J V}^{\prime \prime}(a) \\
& \left.+(1-2 s) \alpha_{1} \alpha_{2} \Pi_{J V}^{\prime}(a)+(1-2 s) \Pi_{J V}^{\prime \prime}(a)\right] \geq 0
\end{aligned}
$$


so that

$$
\begin{aligned}
& \frac{d \Pi_{M}}{d s} \geq 0 \Leftrightarrow \\
& {\left[s \alpha_{2}\left(\alpha_{1}-1\right)+(s-1) \alpha_{1}\left(\alpha_{2}-1\right)+(1-2 s) \alpha_{1} \alpha_{2}\right] \Pi_{J V}^{\prime}(a)} \\
& +\underbrace{(s+s-1+1-2 s)}_{=0} \alpha_{1} \alpha_{2} \Pi_{J V}^{\prime \prime}(a) \geq 0
\end{aligned}
$$

Since the last term is null and $\Pi_{J V}^{\prime}(a)>0$ the total derivative of $\Pi_{M}$ is given by the terms in square brackets which can be rewritten as

$$
\begin{aligned}
& \frac{d \Pi_{M}}{d s} \geq 0 \Leftrightarrow \\
& s \alpha_{2} \alpha_{1}-s \alpha_{2}+s \alpha_{1} \alpha_{2}-s \alpha_{1}-\alpha_{1} \alpha_{2}+\alpha_{1}+\alpha_{1} \alpha_{2}-2 s \alpha_{1} \alpha_{2} \geq 0
\end{aligned}
$$

or

$$
\begin{aligned}
& \frac{d \Pi_{M}}{d s} \geq 0 \Leftrightarrow \\
& \underbrace{s \alpha_{1} \alpha_{2}+s \alpha_{1} \alpha_{2}-2 s \alpha_{1} \alpha_{2}}_{=0}-s\left(\alpha_{1}+\alpha_{2}\right)+\alpha_{1}+\underbrace{\alpha_{1} \alpha_{2}-\alpha_{1} \alpha_{2}}_{=0} \geq 0
\end{aligned}
$$

hence

$$
\frac{d \Pi_{M}}{d s} \geq 0 \Leftrightarrow s \leq \frac{\alpha_{1}}{\alpha_{1}+\alpha_{2}}
$$

which lead to the final optimal sharing scheme as stated in equation (11). Q.E.D.

\section{References}

[1] Anbarci N., Lemke R. and Roy S., (2002), "Inter-firm complementarities in $\mathrm{r} \& \mathrm{~d}$ : a re-examination of the relative performance of joint ventures", International Journal of Industrial Organization, 20 (2), 191-213.

[2] Asiedu, E. and Esfahani, H. S., (2001), "Ownership Structure in Foreign Direct Investments Projects", Review of Economics and Statistics, 83 (4), 647-662.

[3] d'Aspremont C. and Jacquemin A., (1988), "Cooperative and Noncooperative R\&D in Duopoly with Spillovers" The American Economic Review, 78 (5), 1133-1137.

[4] Battacharya S. and Lafontaine F., (1995), " Double-sided moral hazard and the nature of share contracts", Rand Journal of Economics, 26 (4), 761-781. 
[5] Belleflamme P. and Bloch F., (2000), "Optimal Ownership Structures in Asymmetric Joint Ventures", Working Paper, no.411, Queen Mary University of London. Research Joint Ventures e Welfare: una rassegna sulla letteratura teorica, Quaderni di Ricerca no.284, Dipartimento di Economia, Universita' Politecnica delle Marche, April 2007. PDF

[6] Blodgett L., (1991), "Partner contributions as predictors of equity share in international joint ventures", Journal of International Business Studies, 22 (1), 63-78.

[7] Caloghirou Y., Ioannides S. and Vonortas N.S., (2003), "Research Joint Ventures", Journal of Economic Surveys, 17 (4), 541-570.

[8] Darrough M. N. and Stoughton N. M., (1989), "A bargaining approach to profit sharing in joint ventures", The Journal of Business, 62 (2), 237-270.

[9] Freshfield Bruckhaus Deringer, (2005), Joint ventures and alliances. An introductory guide, Freshfield Bruckhaus Deringer Publications.

[10] Grossman S.J. and Hart O.D., (1986), "The Costs and Benefits of Ownership: A Theory of Vertical and Lateral Integration", The Journal of Political Economics, 94 (4), 691 - 719.

[11] Hagerdoon J., Link A. N. and Vonortas N. S., (1999), "Research Partnerships", Research Policy, 29 (4-5), 567-586.

[12] Hart O.D. and Moore J., (1990), "Property Rights and the Nature of the Firm”, The Journal of Political Economics , 98(6), 1119 - 1158.

[13] Lin P. and Saggi K., (2004), "Ownership Structure and Technological Upgrading in International Joint Ventures", Review of Development Economics, 8 (2), 279 - 294.

[14] Makino S. and Beamish P. W., (1998), "Performance and Survival of Joint Ventures with Non-Conventional Ownership Structures", Journal of International Business Studies, 29 (4), 797-918.

[15] Nakamura M., (2005), "Joint venture instability, learning and the relative bargaining power of the parent firms", International Business Review, 14 (4), 465-493.

[16] Nakamura M. and Yeung B., (1994), "On the determinants of Foreign Ownership Shares: Evidence from US Firms' Joint Ventures in Japan", Managerial and Decision Economics, 15 (2), 95-106. 
[17] OECD, Directorate for Financial, Fiscal and Enterprise Affairs Comitee on Competition Law and Policy, Competition Issues in Joint Ventures, 2001.

[18] Veugelers R. and Kestelkoot K., (1996), "Bargained Shares in Joint Ventures Among Asymmetric Partners: Is the Matthew Effect Catalyzying?", Journal of Economics, 64 (1), 23-51. 


\section{Recent titles}

\section{CORE Discussion Papers}

2007/80. Andrea SILVESTRINI. Testing fiscal sustainability in Poland: a Bayesian analysis of cointegration.

2007/81. Jean-François MAYSTADT. Does inequality make us rebel? A renewed theoretical model applied to South Mexico.

2007/82. Jacques H. DREZE, Oussama LACHIRI and Enrico MINELLI. Shareholder-efficient production plans in a multi-period economy.

2007/83. Jan JOHANNES, Sébastien VAN BELLEGEM and Anne VANHEMS. A unified approach to solve ill-posed inverse problems in econometrics.

2007/84. Pablo AMOROS and M. Socorro PUY. Dialogue or issue divergence in the political campaign?

2007/85. Jean-Pierre FLORENS, Jan JOHANNES and Sébastien VAN BELLEGEM. Identification and estimation by penalization in nonparametric instrumental regression.

2007/86. Louis EECKHOUDT, Johanna ETNER and Fred SCHROYEN. A benchmark value for relative prudence.

2007/87. Ayse AKBALIK and Yves POCHET. Valid inequalities for the single-item capacitated lot sizing problem with step-wise costs.

2007/88. David CRAINICH and Louis EECKHOUDT. On the intensity of downside risk aversion.

2007/89. Alberto MARTIN and Wouter VERGOTE. On the role of retaliation in trade agreements.

2007/90. Marc FLEURBAEY and Erik SCHOKKAERT. Unfair inequalities in health and health care.

2007/91. Frédéric BABONNEAU and Jean-Philippe VIAL. A partitioning algorithm for the network loading problem.

2007/92. Luc BAUWENS, Giordano MION and Jacques-François THISSE. The resistible decline of European science.

2007/93. Gaetano BLOISE and Filippo L. CALCIANO. A characterization of inefficiency in stochastic overlapping generations economies.

2007/94. Pierre DEHEZ. Shapley compensation scheme.

2007/95. Helmuth CREMER, Pierre PESTIEAU and Maria RACIONERO. Unequal wages for equal utilities.

2007/96. Helmuth CREMER, Jean-Marie LOZACHMEUR and Pierre PESTIEAU. Collective annuities and redistribution.

2007/97. Mohammed BOUADDI and Jeroen V.K. ROMBOUTS. Mixed exponential power asymmetric conditional heteroskedasticity.

2008/1. Giorgia OGGIONI and Yves SMEERS. Evaluating the impact of average cost based contracts on the industrial sector in the European emission trading scheme.

2008/2. Oscar AMERIGHI and Giuseppe DE FEO. Privatization and policy competition for FDI.

2008/3. Wlodzimierz SZWARC. On cycling in the simplex method of the Transportation Problem.

2008/4. John-John D'ARGENSIO and Frédéric LAURIN. The real estate risk premium: A developed/emerging country panel data analysis.

2008/5. Giuseppe DE FEO. Efficiency gains and mergers.

2008/6. Gabriella MURATORE. Equilibria in markets with non-convexities and a solution to the missing money phenomenon in energy markets.

2008/7. Andreas EHRENMANN and Yves SMEERS. Energy only, capacity market and security of supply. A stochastic equilibrium analysis.

2008/8. Géraldine STRACK and Yves POCHET. An integrated model for warehouse and inventory planning.

2008/9. Yves SMEERS. Gas models and three difficult objectives.

2008/10. Pierre DEHEZ and Daniela TELLONE. Data games. Sharing public goods with exclusion.

2008/11. Pierre PESTIEAU and Uri POSSEN. Prodigality and myopia. Two rationales for social security.

2008/12. Tim COELLI, Mathieu LEFEBVRE and Pierre PESTIEAU. Social protection performance in the European Union: comparison and convergence. 


\section{Recent titles}

\section{CORE Discussion Papers - continued}

2008/13. Loran CHOLLETE, Andréas HEINEN and Alfonso VALDESOGO. Modeling international financial returns with a multivariate regime switching copula.

2008/14. Filomena GARCIA and Cecilia VERGARI. Compatibility choice in vertically differentiated technologies.

2008/15. Juan D. MORENO-TERNERO. Interdependent preferences in the design of equal-opportunity policies.

2008/16. Ana MAULEON, Vincent VANNETELBOSCH and Wouter VERGOTE. Von NeumannMorgenstern farsightedly stable sets in two-sided matching.

2008/17. Tanguy ISAAC. Information revelation in markets with pairwise meetings: complete information revelation in dynamic analysis.

2008/18. Juan D. MORENO-TERNERO and John E. ROEMER. Axiomatic resource allocation for heterogeneous agents.

2008/19. Carlo CAPUANO and Giuseppe DE FEO. Mixed duopoly, privatization and the shadow cost of public funds.

2008/20. Helmuth CREMER, Philippe DE DONDER, Dario MALDONADO and Pierre PESTIEAU. Forced saving, redistribution and nonlinear social security schemes.

2008/21. Philippe CHEVALIER and Jean-Christophe VAN DEN SCHRIECK. Approximating multiple class queueing models with loss models.

2008/22. Pierre PESTIEAU and Uri M. POSSEN. Interaction of defined benefit pension plans and social security.

2008/23. Marco MARINUCCI. Optimal ownership in joint ventures with contributions of asymmetric partners.

\section{Books}

Y. POCHET and L. WOLSEY (eds.) (2006), Production planning by mixed integer programming. New York, Springer-Verlag.

P. PESTIEAU (ed.) (2006), The welfare state in the European Union: economic and social perspectives. Oxford, Oxford University Press.

H. TULKENS (ed.) (2006), Public goods, environmental externalities and fiscal competition. New York, Springer-Verlag.

V. GINSBURGH and D. THROSBY (eds.) (2006), Handbook of the economics of art and culture. Amsterdam, Elsevier.

J. GABSZEWICZ (ed.) (2006), La différenciation des produits. Paris, La découverte.

L. BAUWENS, W. POHLMEIER and D. VEREDAS (eds.) (2008), High frequency financial econometrics: recent developments. Heidelberg, Physica-Verlag.

P. VAN HENTENRYCKE and L. WOLSEY (eds.) (2007), Integration of AI and OR techniques in constraint programming for combinatorial optimization problems. Berlin, Springer.

\section{CORE Lecture Series}

C. GOURIÉROUX and A. MONFORT (1995), Simulation Based Econometric Methods.

A. RUBINSTEIN (1996), Lectures on Modeling Bounded Rationality.

J. RENEGAR (1999), A Mathematical View of Interior-Point Methods in Convex Optimization.

B.D. BERNHEIM and M.D. WHINSTON (1999), Anticompetitive Exclusion and Foreclosure Through Vertical Agreements.

D. BIENSTOCK (2001), Potential function methods for approximately solving linear programming problems: theory and practice.

R. AMIR (2002), Supermodularity and complementarity in economics.

R. WEISMANTEL (2006), Lectures on mixed nonlinear programming. 
Département des Sciences Économiques de l'Université catholique de Louvain

Institut de Recherches Économiques et Sociales

Place Montesquieu, 3

1348 Louvain-la-Neuve, Belgique 